\title{
STABILITY OF THE JUNGTION OF AN ICE SHEET AND AN ICE SHELF
}

\section{By J. Weertman}

(Departments of Materials Science and Geological Sciences, Northwestern University, Evanston, Illinois 6020 I, U.S.A. and U.S. Army Cold Regions Research and Engineering Laboratory, Hanover, New Hampshire 03755, U.S.A.)

\begin{abstract}
An analysis is made of the steady-state size of a two-dimensional ice sheet whose base is below sea-level and which terminates in floating ice shelves. Under the assumption of perfect plasticity it is found that an ice sheet placed on a bed whose surface was initially flat cannot exist if the depth of the bed below sea-level exceeds a critical depth. If this depth is less than the critical level, the ice sheet extends out to the edge of the continental shelf. Similar results are found with more realistic assumptions about the laws governing the flow of ice. If the bed slopes away from the centre, the ice sheet can have a stable width that increases in value as the accumulation rate increases or as sea-level is loweref. It is not possible to decide whether or not the West Antarctic ice sheet is in stable equilibrium. It is entirely possible that this ice sheet is disintegrating at present, as suggested by Hughes.

RÉsumé. Stabilité de la jonction entre une calotte glaciaire et une plateforme de glace. On fait une analyse de la forme d'équilibre d'une calotte à deux dimensions, dont la base est au-dessus du niveau le la mer et qui se termine en glaces flottantes. Avec l'hypothèse d'une plasticité parfaite, on trouve qu'une calotte placée sur un lit dont la surface était initialement plate ne peut exister si la profondeur du lit en-dessous du niveau de la mer excède une profondeur critique. Si cette profondeur est moindre que le niveau critique, la calotte s'étend en dehors des limites du plateau continental. Des résultats semblables sont obtenus à partir d'hypothèses plus réalistes, sur les lois gouvernant l'écoulement de la glace. Si le lit plonge en s'éloignant du centre, la calotte peut avoir une largeur stable qui croît lorsque le taux d'accumulation augmente ou lorsque le niveau de la mer s'abaisse. Il n'est pas possible de déceler si la calotte glaciaire de l'Ouest. Antarctique est ou non en équilibre stable. Il est tout à fait possible que cette calotte soit actuellement en cours de désintégration, comme le suggère Hughes.

Zusammenfassung. Stabilität der Verbindung zwischen einem Eisschild und einem Schelfeis. Eine Untersuchung galt der stationären Ausdehnung eines zweidimensionalen Eisschildes, dessen Basis unter dem Meeresniveau liegt und der in schwimmenden Schelfeisen endet. Unter der Voraussetzung vollkommener Plastizität wurde gefunden, dass ein Eisschild, der auf einen ursprünglich flachen Untergrund gelagert ist, nicht bestehen kann, wenn die Tiefe der Basis unter dem Meeresniveau einen kritischen Wert überschreitet. Wird dieser Wert nicht erreicht, dann dehnt sich der Eisschild bis zum Rand des Festlandsockels aus. Ähnliche Ergebnisse wurden mit realistischeren Annahmen über die Gesetzmässigkeiten des Eisfliessens gefunden. Wenn der Untergrund vom Zentrum nach aussen hin abfällt, kann der Eisschild eine stabile Ausdehnung annehmen, die mit wachsender Akkumulation oder mit fallendem Meeresspiegel zunimmt. Es ist nicht möglich zu entscheiden, ob der Westantarktische Eisschild sich in stabilem Gleichgewicht befindet oder nıcht. Es ist durchaus möglich, dass sich dieser Eisschild gegenwärtig auf löst, wie Hughes vermutet.
\end{abstract}

\section{INTRODUCTION}

The junction of an ice sheet and an ice shelf occurs at the point, as the ice flows to the sea, at which the ice mass first is afloat and consequently loses contact with the bed. Hughes (r972) has suggested that the position of the junction of the West Antarctic ice sheet and of the Ross Ice Shelf is unstable. He concluded that at the present time this junction is retreating into the interior of West Antarctica at the velocity of about $70 \mathrm{~m} \mathrm{a}^{-1}$.

The problem of junction stability that Hughes' work has emphasized is important. Large shifts in the position of the ice sheet-ice shelf junction produce relatively large changes in the thickness of an ice sheet. In this paper we attempt to obtain, for the two dimensional problem, the basic equations that determine the position of the region in which an ice sheet turns into a floating ice shelf; we also examine the conditions that must be satisfied if the ice sheet is even to exist.

\section{THEORY}

Consider a symmetric, two-dimensional ice sheet. Let ice shelves be attached to both sides of this ice sheet as shown in Figure 1 . Let $D(x)$ represent the depth of the bedrock 
below sea-level, where $x$ is the distance measured in the horizontal direction from the center of the ice sheet. (We consider $x$ always to be a positive quantity whether it is measured to the right or to the left of the center of the ice sheet.) Assume that if no ice sheet were present $D(x)$ would be a linearly increasing function of distance $x$ out to the edges of the continent. Thus

$$
D(x)=D_{0}+\beta x
$$

for $0 \leqslant x \leqslant L_{0}$ and, for all practical purposes,

$$
D(x)=\infty
$$

for $x>L_{0}$. Here $x=L_{0}$ is the position of the edges of the continent, $D_{0}$ is a constant, and $\beta$ is the slope of the bed rock away from the center of the continent. (We consider only values of $\beta$ in the range $\beta \geqslant 0$.)

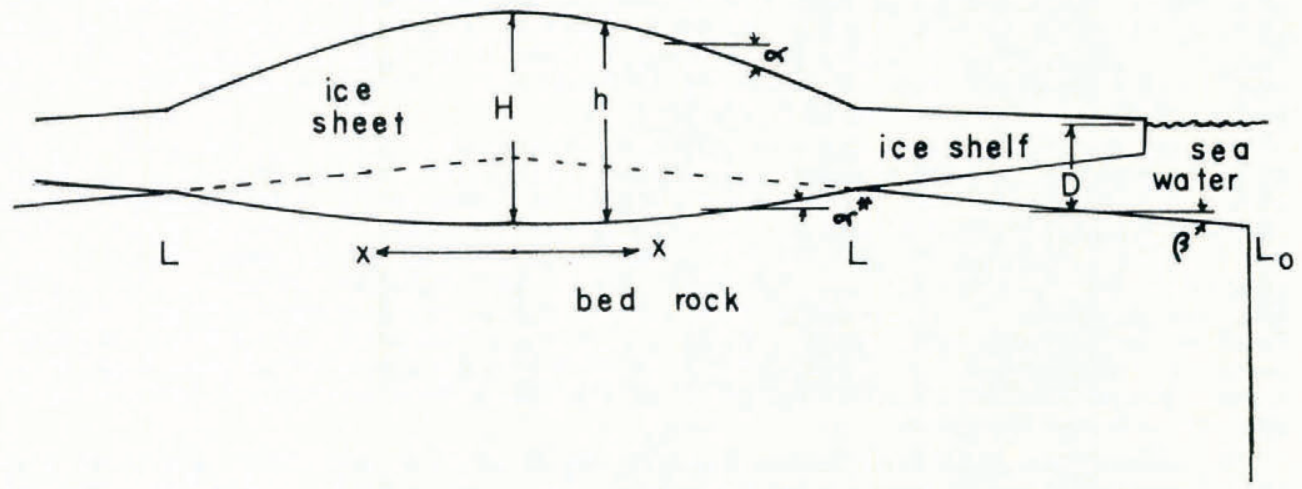

Fig. 1. Cross-section of ice sheet with altached ice shelves.

Isostatic sinking occurs under an ice sheet. If $h(x)$ is the thickness of the ice sheet, $D(x)$ after isostatic sinking is given by

$$
D(x)=\left(D_{0}+\beta x\right)\left(\mathrm{r}-\rho_{\mathrm{w}} / \rho_{\mathrm{r}}\right)+\left(\rho / \rho_{\mathrm{r}}\right) h(x)
$$

in the region $0 \leqslant x \leqslant L$ where $x=L$ gives the position of the edges of the ice sheet. Of necessity the position $L$ of the junction between the ice sheet and an ice shelf must satisfy the relationship $L \leqslant L_{0}$. The quantities $\rho, \rho_{\mathrm{w}}$ and $\rho_{\mathrm{r}}$ in Equation (2) are the average densities of ice, sea-water, and bedrock, respectively. In the region under the floating ice shelf $(x \geqslant L)$ the depth $D(x)$ is given by Equation ( $\mathrm{I}$ ).

A rise or fall in the sea-level results in an identical increase or decrease in the value of $D_{0}$ in Equations (I) and (2). The change in the value of the ice sheet-ice shelf junction position $L$ with change in sea-level can be found only from an analysis of the mechanics of flow of ice sheets and ice shelves.

Assume that the ice sheet and ice shelves of Figure $I$ are in a steady-state condition. From a mass balance argument it can be seen that

$$
U h=\int_{0}^{x} a \mathrm{~d} x
$$

where $a(x)$ is the accumulation rate at $x$ and $U(x)$ is the average value of the horizontal ice velocity component. If there is melting or freezing at the bottom surface this mass loss or gain must be included in the term $a(x)$.

Differentiation of Equation (3) produces the equation

$$
h \dot{\epsilon}-U \gamma=a
$$


where $\dot{\epsilon}=\mathrm{d} U / \mathrm{d} x$ is the longitudinal strain-rate and $\gamma=-\mathrm{d} h / \mathrm{d} x=\alpha+\alpha^{\star}$, where $\alpha$ is the slope of the upper ice surface (considered to be a positive quantity if the upper surface decreases in elevation as $x$ increases) and $\alpha^{\star}$ is the slope of the bottom ice surface (considered to be a positive quantity if the lower ice surface increases in elevation with increasing value of $x$ ).

Assume that, in the case of the ice sheet, the value of the velocity is given approximately by the equation (see chapter 9 of Patterson, 1969)

$$
U \approx B\left(\tau / \tau_{0}\right)^{n} \approx B\left(\rho g h \alpha / \tau_{0}\right)^{n}
$$

where $B, \tau_{0}$ and $n$ are constants, and $\tau$ is the basal shear stress. The value of $n$ and the expression $B / \tau_{0}{ }^{n}$ depend on factors such as whether or not sliding occurs, and the temperature distribution within the ice sheet. Reasonable values of $B$ and $n$ are $n \approx 3$ and $B \approx 50 \mathrm{~m} \mathrm{a}^{-1}$ if $\tau_{0}=\mathrm{I}$ bar.

Equation (5) is derived (Paterson, 1969, chapter 9) under the assumption that the dominant stress producing flow in an ice sheet is the shear stress that acts across any surface that is approximately parallel to the top or bottom surface. When large longitudinal stresses are present this equation is not valid.

In the ice shelves $U$ is given by

$$
U=U_{L}+\int_{i}^{x} \dot{\epsilon} \mathrm{d} x
$$

where the longitudinal creep rate is

$$
\dot{\boldsymbol{\epsilon}}=A\left(\Delta \rho g h / 4 \tau_{0}\right)^{m} .
$$

In Equations (6) and (7), $U_{L}$ is the horizontal velocity at $x=L, \Delta \rho=\rho_{\mathrm{w}}-\rho, m \approx n \approx 3$, and $A$ is a constant whose value depends on the temperature and density profile of an ice shelf. A reasonable value of $A$ is $\approx 2 \times 10^{-3} \mathrm{a}^{-1}$ for $\tau_{0}=\mathrm{I}$ bar. Equation (7) is found from the analysis of the creep rate of an unconfined, two-dimensional ice shelf (Weertman, 1957).

\section{Perfegtly plastic approximation}

Considerable insight is often gained in problems in glacier mechanics by making the assumption that ice is a perfectly plastic solid. Such is the case with the ice sheet-ice shelf junction problem.

The perfect plasticity approximation is made in our previous equations by taking the limit of $n=m=\infty$. If $n$ is set equal to $\infty$ in Equation (7) for an ice shelf with a positive accumulation, that equation predicts that the ice shelf must have the thickness $h_{1}$ p (independent of $x$ ) equal to

$$
h_{\mathrm{I}} \mathrm{p}=4 \tau_{0} / \Delta \rho g .
$$

(If the thickness of an ice shelf were greater than $h_{\mathrm{I}}$ it would strain at an infinite rate until its thickness were reduced to the value $h_{\mathrm{I}} \mathrm{p}$. If the thickness were smaller than $h_{\mathrm{I}}$ the ice shelf would not creep but its thickness would increase in time because of the positive accumulation rate until it reached the value $h_{1}$ p.) For $\Delta \rho \approx 0.1 \rho_{\mathrm{W}}$ and $\tau_{0}=\mathrm{I}$ bar the value of $h_{\mathrm{I}} \mathrm{p}$ is approximately $400 \mathrm{~m}$.

By similar reasoning it can be seen from Equation (5) that the basal shear stress of the ice sheet must take on the value $\tau=\tau_{0}$. The ice sheet profile thus is found by integrating the equation

where

$$
\rho g h \alpha=\tau_{0}
$$

If the ice sheet bed was flat before the ice sheet was placed on it $(\beta=0)$ the solution of Equations (9) and (I0) is

$$
h^{2}=H^{2}-2 \tau_{0} x / \rho g\left(\mathrm{I}-\rho / \rho_{\mathrm{r}}\right)=h_{2}^{2}+2 \tau_{0}(L-x) / \rho g\left(\mathrm{I}-\rho / \rho_{\mathrm{r}}\right)
$$


where $H$, given by

$$
H^{2}=h_{2}^{2}+2 \tau_{0} L / \rho g\left(\mathrm{r}-\rho / \rho_{\mathrm{r}}\right)
$$

is the thickness of the ice sheet at the center $(x=0)$ and $h_{2}$ is the thickness of the ice sheet at its edges $(x=L)$. Because the ice sheet is afloat at its edges the thickness $h_{2}$ is equal to

$$
h_{2}=\left(\rho_{\mathrm{w}} / \rho\right) D(L) .
$$

When $\beta \neq 0$ the ice-sheet profile is given by the equation

$$
\begin{gathered}
(H-h)-(\mathrm{I} / A) \ln [(A H-\mathrm{I}) /(A h-\mathrm{I})]=\tau_{0} A x / \rho g\left(\mathrm{I}-\rho / \rho_{\mathbf{r}}\right) \\
\text { where } \quad A=\left(\beta \rho g / \tau_{0}\right)\left(\mathrm{I}-\rho_{\mathrm{w}} / \rho_{\mathrm{r}}\right) .
\end{gathered}
$$

The value of $H$ in Equation (14) is found by setting $h=h_{2}$ at $x=L$.

\subsection{Condition at ice sheet-ice shelf junction}

At $x=L$, the position of the junction of the ice sheet and an ice shelf, the thickness of the ice shelf, $h=h_{2}$, is such that the ice sheet is afloat. The ice shelf also is afloat. Thus the thickness of the ice shelf, $h=h_{\mathrm{I}}$, must satisfy the condition

$$
h_{1 \mathrm{p}} \leqslant h_{2} \text {. }
$$

Suppose $h_{1 \mathrm{p}}$ were appreciably smaller than $h_{2}$, a situation illustrated in Figure 2. The ice sheet is chopped off essentially at $x=L$. The effect of this truncation at the edge of the ice sheet is to cause a large longitudinal tensile stress to be set up in the ice sheet near its edge. The magnitude of this tensile stress must be of the same order as that of the stress existing in

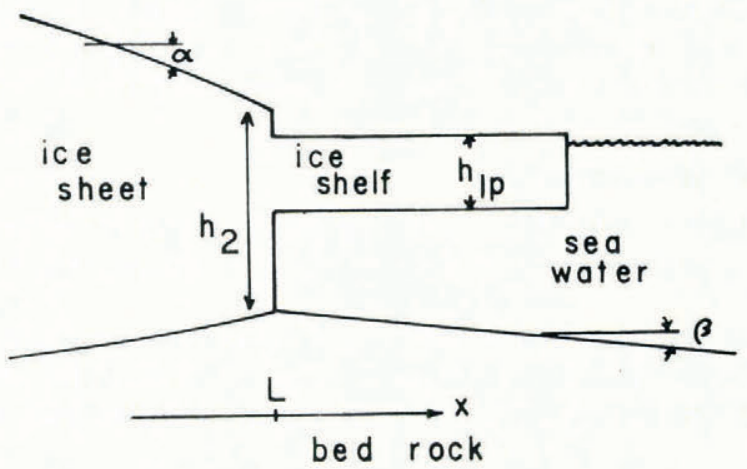

Fig. 2. Junction between ice sheet and ice shelf. No restriction on thickness of ice sheet at $x=L$. Perfect plasticity approximation.

an ice shelf of thickness $h_{2}$. The longitudinal strain-rate in the ice sheet near its edge must thus be of the order given by Equation (7). But since $h_{2} \gg h_{1}$ p this strain-rate is infinite if ice is a perfectly plastic solid. Therefore it is not possible to have $h_{2} \gg h_{1}$ and have the ice sheet and the ice shelves in a steady-state condition.

We conclude that

$$
h_{2} \approx h_{1} \mathrm{p}
$$

is a necessary condition at the junction of an ice sheet and an ice shelf.

An appreciable longitudinal tensile stress exists within the ice near the edge of an ice sheet even if Equation ( 17 ) is satisfied. The tensile stress that exists within an ice shelf cannot die out abruptly at the ice sheet-ice shelf junction. The basal shear stress near the edge of the ice sheet must be reduced in value in order that the effective stress that produces plastic deformation does not exceed the limit $\tau_{0}$. (The effective stress that produces plastic deformation is 
equal to the sum of the squares of the deviator stress components divided by $\sqrt{ } \mathbf{2}$ (Paterson, I969).) Therefore when Equation (9) is used to determine the ice-sheet profile a reduced value of the term $\tau_{0}$ should be employed near the edge of the ice sheet.

Figure 3 shows the cross-section of the junction region between the ice sheet and an ice shelf when $h_{2} \approx h_{\mathrm{I}}$. . No sharp change in ice thickness occurs across this zone. The slope of the upper ice surface is reduced in the transition region at the edge of the ice sheet because of the need to reduce the basal shear stress when a longitudinal tensional stress is present.

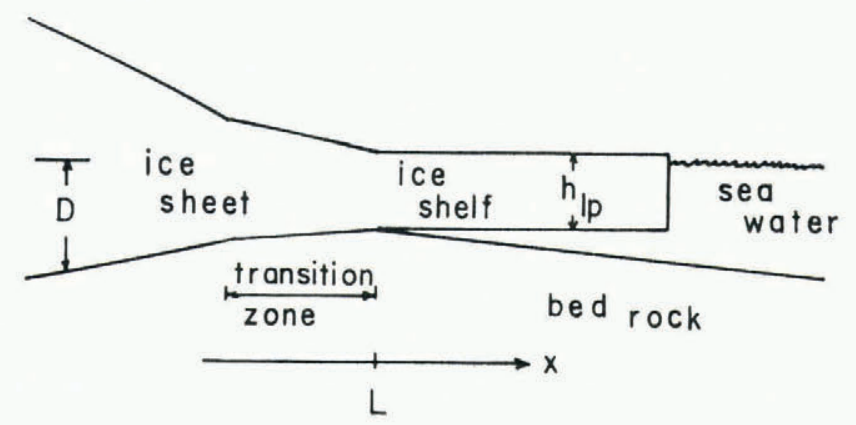

Fig. 3. Function between ice sheet and ice shelf. A transition region exists in which the longitudinal tensile stress and the shear stress are comparable in magnitude. Perfect plasticity approximation.

The junction between the ice sheet and the ice shelf occurs at that value of $x=L$ for which

$$
h_{2} \approx h_{1 \mathrm{p}}=\left(\rho_{\mathrm{w}} / \rho\right) D(L) .
$$

When Equation (1a) is inserted in Equation (18) the following equation is found for $L$ :

$$
L=\left(\left[\rho h_{1 \mathrm{p}} / \rho_{\mathrm{w}}\right]-D_{\mathrm{o}}\right) / \beta=\left(4 \tau_{\mathrm{o}} \rho / \Delta \rho \rho_{\mathrm{w}} g-D_{\mathrm{o}}\right) / \beta .
$$

If the value of $L$ predicted by Equation (19) is larger than $L_{0}$ (see Fig. I) the edge of the ice sheet occurs at the value $x=L_{0}$ instead of $x=L$. In this situation the edge of the ice sheet cannot be afloat because $h_{1} \mathrm{p}>\left(\rho_{\mathrm{w}} / \rho\right) D\left(L_{0}\right)$. Under these circumstances the equivalent of ice falls must exist at the edges of the ice sheet. The ice shelves form below these ice falls.

A bed that was flat before an ice sheet was placed on it $(\beta=0)$ becomes entirely covered by ice out to $x=L_{0}$ if $h_{\mathrm{t}}>\left(\rho_{\mathrm{w}} / \rho\right) D_{0}$; if $h_{1}<\left(\rho_{\mathrm{w}} / \rho\right) D_{0}$ no ice sheet can exist at all. In the former case the ice sheet would turn catastrophically into a floating ice shelf if the sea-level were to rise until $h_{1 \mathrm{p}}$ becomes less than $\left(\rho_{\mathrm{w}} / \rho\right) D_{0}$.

\section{ReAlistic Flow LAW}

How are the results of the last section modified if ice is assumed to obey the more realistic flow laws of Section 2 that use finite values of $n$ and $m(m \approx n \approx 3)$ rather than the infinite values of the perfectly plastic approximation?

The thickness of the ice shelves no longer is a constant. Instead of the unique thickness given by Equation (8) the thickness $h_{1}$ of the ice shelf at the junction is given by the following equation (found by combining Equations (4) and (7)):

$$
h_{1}=h_{1}\left\{(1 / A)\left[\left(\langle a\rangle L \gamma_{1} / h_{1} \mathrm{p}^{2}\right)+\left(a_{1} h_{1} / h_{1} p^{2}\right)\right]\right\}^{1 /(m+2)}
$$

where $h_{1}$ is given by Equation (8), $\gamma_{1}$ and $a_{1}$ are the values of $\gamma$ and $a$ for the ice shelf at the junction, and $\langle a\rangle$ is the average accumulation rate given by

$$
\langle a\rangle=L^{-1} \int_{0}^{L} a \mathrm{~d} x \text {. }
$$


Because the exponent $\mathrm{I} /(\mathrm{m}+2)$ in Equation (2O) is approximately equal to $\frac{1}{5}$, very large changes in $\langle a\rangle, a_{1}$ and $\gamma_{1}$ are required to change the value of $h_{1}$ by more than a factor of 2 to 3 . Thus the results in Section 3 are expected to remain valid as a first approximation.

In the transition region (see Figure 3 ) at the edge of an ice sheet longitudinal as well as shear stresses are expected to be important. The deformation and flow in the transition region thus are determined by the triaxial creep equations of Nye (see chapter 6 of Paterson, 1969). The following equation, that takes the triaxial stresses into account and replaces Equation (7), gives a rough approximation of the longitudinal strain-rate $\dot{\epsilon}$ in the transition zone

$$
\dot{\boldsymbol{\epsilon}}=A\left(\Delta \rho g h / 4 \tau_{0}\right)\left\{c_{1}\left(\Delta \rho g h / 4 \tau_{0}\right)^{2}+c_{2}\left(\rho g h \alpha / \tau_{0}\right)^{2}\right\}^{(m-1) / 2}
$$

where $c_{1}$ and $c_{2}$ are constants of order of magnitude of $\mathrm{x}$.

Similarly Equation (5) for the average ice velocity $U$ is replaced by the equation

$$
U=B\left(\rho g h \alpha / \tau_{0}\right)\left\{c_{1}\left(\Delta \rho g h / 4 \tau_{0}\right)^{2}+c_{2}\left(\rho g h \alpha / \tau_{0}\right)^{2}\right\}^{(n-1) / 2}
$$

as a rough approximation in the transition region.

Combining Equations (4), (22) and (23) gives

$$
\alpha \gamma=(A h / 4 B)(\Delta \rho / \rho)
$$

when $n=m$ and the approximation $U \gamma \gg a$ is valid. From Equation (2) it is possible to show that

$$
\gamma=\left\{\alpha-\beta\left(\mathbf{I}-\rho_{\mathrm{w}} / \rho_{\mathbf{r}}\right)\right\} /\left(\mathrm{I}-\rho / \rho_{\mathbf{r}}\right) .
$$

Combining Equations (3) and (23) and setting $n=3$ gives

$$
\alpha=(\langle a\rangle L / 4 B)(\Delta \rho / \rho)\left(h_{1} \mathrm{p}^{3} / h^{4}\right) /\left\{c_{\mathrm{I}}+c_{2}(4 \rho \alpha / \Delta \rho)^{2}\right\} \text {. }
$$

Combining Equations (24), (25) and (26) and assuming that $\alpha \gg \beta$ gives for the upper surface slope $\alpha$ the equation

$$
\begin{aligned}
\alpha=\left\{A^{4} B^{-5}(\Delta \rho / 4 \rho)^{5}\left(\mathrm{I}-\rho / \rho_{\mathrm{r}}\right)^{4} h_{\mathrm{I}} \mathrm{p}^{3}\langle a\rangle L /\left[c_{\mathrm{r}}+c_{2}(4 \rho \alpha / \Delta \rho)^{2}\right]\right\}^{1 / 9} & \approx \\
\approx & \operatorname{0.\mathrm {I}}\left(A^{4}\langle a\rangle L h_{\mathrm{I}} \mathrm{p}^{3} / B^{5}\right)^{1 / 9} .
\end{aligned}
$$

Combining Equations (24) and (27) gives the following equation for the ice thickness $h=h_{2}$ in the transition region

$$
h_{2} \approx(\text { o.or })\left(\langle a\rangle^{2} L^{2} h_{1} \mathrm{p}^{6} / A B\right)^{1 / 9}(4 \rho / \Delta \rho) /\left(\mathrm{I}-\rho / \rho_{\mathrm{r}}\right) .
$$

For $\langle a\rangle=0.1 \mathrm{~m} \mathrm{a}^{-1}, L=\mathrm{I} 000 \mathrm{~km}, h_{\mathrm{1}}=400 \mathrm{~m}, A=2 \times 10^{-3} \mathrm{a}^{-1}, B=50 \mathrm{~m} \mathrm{a}^{-1}$, $\Delta \rho / \rho=0.1$, and $\rho / \rho_{\mathrm{r}}=\frac{1}{3}$ the thickness $h_{2}=543 \mathrm{~m}$ and the slope $\alpha=0.019$. These results justify a posteriori the assumptions that $U_{\gamma}=\langle a\rangle L \gamma / h \gg a$ and $\alpha \gg \beta$ for reasonable values of $a, L$ and $\beta$.

The distance $x=L$ to the edge of an ice sheet can be found from Equation (19) if $h_{2}$ is substituted for $h_{1}$ in that equation. The following is found for $L$ :

$$
\beta L+D_{0}=g L^{2 / 9}
$$

where

$$
g=(0.01)\left(\rho / \rho_{\mathrm{w}}\right)\left(\langle a\rangle^{2} h_{\mathrm{I}} \mathrm{p}^{6} / A B\right)^{1 / 9}(4 \rho / \Delta \rho) /\left(\mathrm{I}-\rho / \rho_{\mathrm{r}}\right)
$$

(The term $g=22.7 \mathrm{~m}^{7 / 9}$ for the values of $\langle a\rangle$, etc., mentioned before.)

The solution for Equation (29) can be found graphically by plotting the function $\beta L+D_{0}$ versus $L$ and the function $g L^{2 / 9}$ versus $L$. Such a plot is given in Figure 4 . Depending upon the values of $\beta$ and $D_{0}$ there may be one, two, or no real, positive values of $L$ that satisfy Equation (29).

When $\beta=0$ and $D_{0}>0$ there is one real, positive value of $L$ that satisfies Equation (29) (see Figure 4). It is given by the equation

$$
L=\left(D_{0} / g\right)^{9 / 2} \text {. }
$$

When $\beta=\mathrm{o}$ a steady-state ice sheet whose half-width $L$ is given by Equation $(3 \mathrm{I})$ clearly is in unstable equilibrium. It only need be noted that Equation (31) predicts that $L$ decreases in 


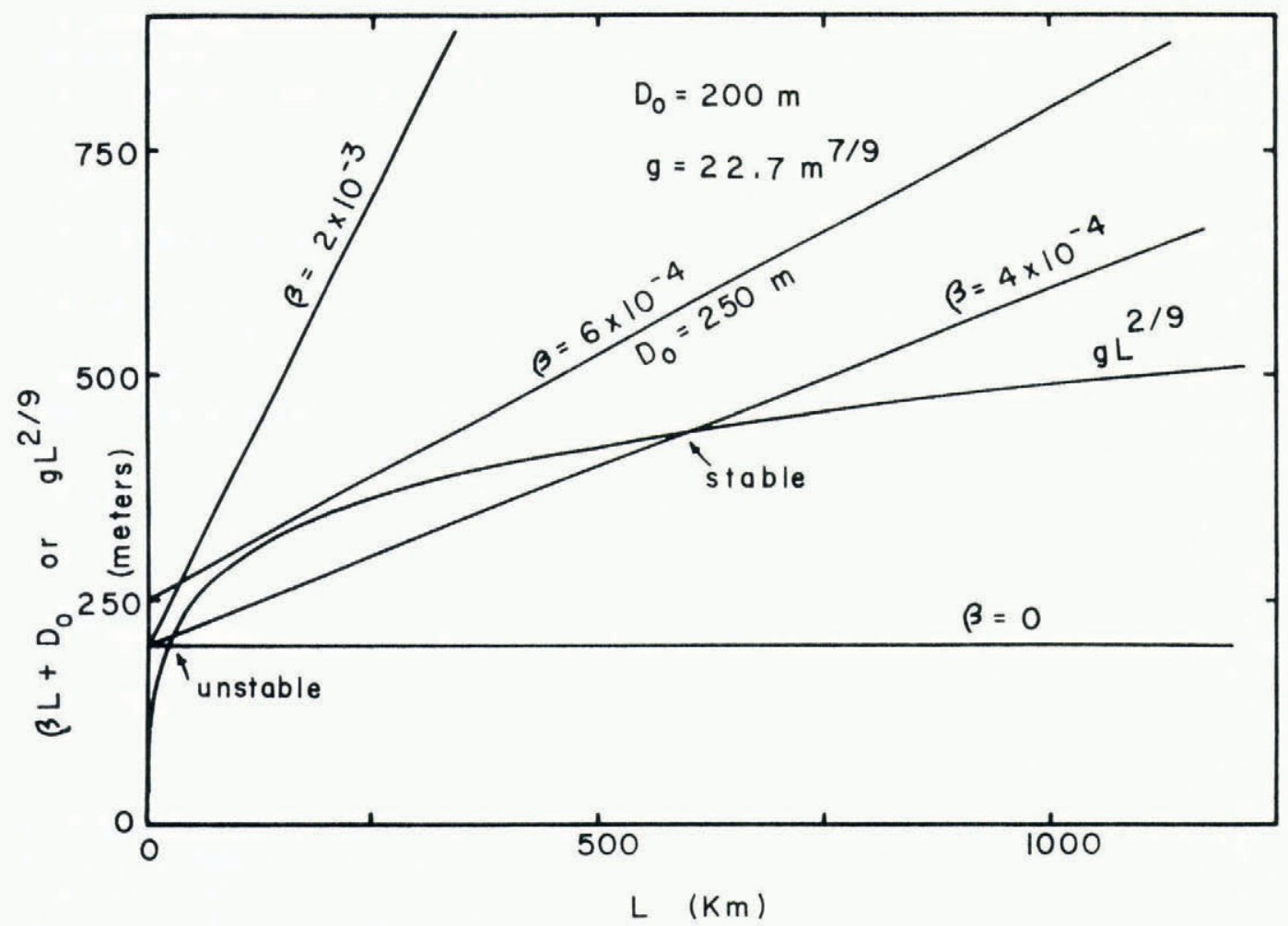

Fig. 4. Plots of the functions $g L^{2 / 9}$ and $\left(\beta L+D_{0}\right)$ versus $L$. Curves plotted for $g=22.7 m^{7 / 9}, D_{0}=200 \mathrm{~m}$ and (for one curve) $250 \mathrm{~m}$, and $\beta=2 \times 10^{-3}, 6 \times 10^{-4}, 4 \times 10^{-4}$ and $o$. Values of $L$ for steady-state ice sheets occur wheie the curves of $g L^{2 / 9}$ and $\left(\beta L+D_{0}\right)$ cross.

value if the accumulation rate $\langle a\rangle$ increases or if the sea-level drops. A non-steady-state ice sheet whose edge occurs at a value of $L$ which is larger than that given by Equation (3I) will grow in size until it reaches the edge of the continental shelf at $x=L_{0}$. If the half-width is smaller than that given by Equation (3I) this ice sheet will shrink with time until it disappears. If $L$ given by Equation $(31)$ is larger than $L_{0}$ clearly no ice sheet can exist. These results are very similar to those found for an ice sheet that obeys the equations of a perfectly plastic solid for the case in which $\beta=0$.

If the curve of the function $\beta L+D_{0}$ intersects the curve of the function $g L^{2 / 9}$ twice (see Figure 4) the intersection corresponding to the smaller value of $L$ represents the solution of a steady-state ice sheet in unstable equilibrium. The other intersection represents an ice sheet in stable equilibrium. For example, if $D_{0}$ is small compared with $h_{2}$ the solution of Equation (3) for the larger value of $L$ is

$$
L \approx(g / \beta)^{9 / 7}-\left(9 D_{0} / 7 \beta\right)
$$

This equation predicts that $L$ increases if $\langle a\rangle$ increases or if the sea-level drops. Equation $(32)$ gives the half-width of an ice sheet that is in stable equilibrium. This result too is analogous to that found for the perfectly plastic approximation when $\beta \neq 0$.

If the value of $L$ for the steady-state ice sheet in unstable equilibrium is such that $\beta L \ll D_{0}$ the solution of Equation (29) is

$$
L \approx\left(D_{0} / g\right)^{9 / 2}+\left(9 \beta D_{0}^{17} / 2 g^{9}\right) .
$$


From Figure 4 it can be seen that if $D_{0}$ and $\beta$ are made sufficiently large in value no solution for $L$ exists. By considering the special case in which the curves of the functions $\beta L+D_{0}$ and $g L^{2 / 9}$ are tangent to each other it is simple to show that no solution exists when the following inequality is satisfied

$$
\beta^{2 / 7} D_{0}>g^{9 / 7}\left\{(2 / 9)^{2 / 7}-(2 / 9)^{9 / 7}\right\} \approx g^{9 / 7} / 2 .
$$

For the value of $g$ given previously $\left(g=22.7 \mathrm{~m}^{7 / 9}\right)$ if the term $\beta^{2 / 7} D_{0}$ is larger than $28 \mathrm{~m}$ no ice sheet can exist.

If the ice sheet is small the assumption that $U_{\gamma}=\langle a\rangle L / h \gg a$ breaks down. In this situation an ice sheet can exist if $h_{1}$, the thickness of the ice shelves given by Equation (20), is larger than $D_{0}$. An approximate half-width for such a small ice sheet can be found by replacing in Equation (I9) the term $h_{\mathrm{I}}$ with the term $h_{\mathrm{I}}$. In the approximation $m=3$ and $\langle a\rangle L \gamma / h \ll a$ the half-width $L$ is given by

$$
L \approx\left[\left(\rho / \rho_{\mathrm{w}}\right)\left(h_{\mathrm{I}} \mathrm{p}^{3} a_{\mathrm{t}} / A\right)^{\mathrm{r} / 4}-D_{\mathrm{o}}\right] / \beta .
$$

Thus if

$$
D_{0}<\left(\rho / \rho_{\mathrm{W}}\right)\left(h_{\mathrm{ID}}{ }^{3} a_{\mathrm{I}} / A\right)^{1 / 4}
$$

an ice sheet can exist.

\section{Discussion}

The results of this paper show that an ice sheet that rests on a flat bed (flat before the ice sheet was placed on it) situated below sea-level is inherently unstable. Depending upon the depth of the bed below sea-level the ice sheet either will shrink in size until it disappears or it will grow until its edge is at the border of the continental shelf. A stable ice sheet can occur if the bed slopes away from the center of the ice sheet. The generalization of our results to other bed shapes is rather obvious.

We have not attempted to analyse the three-dimensional situation in which an ice sheet flows into a confined ice shelf. The results of Thomas (1973[a], r973[b]) and Budd (r966) on the deformation of confined ice shelves might be used to extend our theory to this situation.

We hope that the theory of this paper can be applied to the question Hughes raised: Is the West Antarctic ice sheet disintegrating? The bedrock under a large fraction of this ice sheet is below sea-level now and would still be below sea-level if the ice sheet were removed and complete isostatic rebound occurred. From the cross-section of the West Antarctic ice sheet through Byrd Station and the Ross Ice Shelf shown in figure 6 in the paper of Hughes (1972) or in figure 4 of Robin and others (1970) the following estimate can be made: $\beta \approx 4 \times \mathrm{IO}^{-4}$ and $D_{0} \approx 200 \mathrm{~m}$. If these values of $\beta$ and $D_{0}$ are inserted into Equation (29) and if $g$ is assumed to equal $22.7 \mathrm{~m}^{7 / 9}$ it is found (see Fig. 4) that $L \approx 700 \mathrm{~km}$ for the stable steady-state ice sheet. This value is approximately the half-width of the present West Antarctic ice sheet along this flow line. However we emphasize strongly that one should not conclude from this calculation, which is only an approximate one, that the present ice sheet is indeed in a stable steady-state condition. If the estimated values of $\beta$ and $D_{0}$ were changed to $\beta \approx 6 \times 10^{-4}$ and $D_{0} \approx 250 \mathrm{~m}$, values well within reasonable error limits, no steady-state ice sheet could exist (see Fig. 4) and the present West Antarctic ice sheet must shrink until it disappears. In addition any complete treatment of this problem must also take into account the fact that fast-moving ice streams exist near the edge of the West Antarctic ice sheet where it flows into the Ross Ice Shelf. It appears within possibility that Hughes' suggestion that the West Antarctic ice sheet is disintegrating is correct. Certainly this suggestion cannot be ruled out as physically unlikely on the basis of our theory and calculations. 


\section{Acknowledgements}

This paper was written as a result of my participation at the Cambridge Workshop on Temperature and Isotopic Profiles in Polar Ice Sheets held at Scott Polar Research Institute, Cambridge, England, in April 1973. I wish to thank the Royal Society of London for a travel grant that made my participation possible and Dr Gordon Robin for the invitation to attend.

MS. received I8 May 1973

\section{REFERENCES}

Budd, W. F. 1966. The dynamics of the Amery Ice Shelf. Journal of Glaciology, Vol. 6, No. 45, p. 335-58.

Hughes, T. J. 1972. Is the west Antarctic ice sheet disintegrating? ISCAP [Ice Streamline Cooperative Antarctic Project] Bulletin (Ohio State University), No. I.

Paterson, W. S. B. I969. The physics of glaciers. Oxford, Pergamon Press. (The Commonwealth and International Library. Geophysics Division.)

Robin, G. de Q., and others. 1970. Radio echo exploration of the Antarctic ice sheet, by G. de Q. Robin, C. W. M. Swithinbank and B. M. E. Smit'.. [Union Géodésique et Géophysique Internationale. Association Internationale d'Hydrologie Scientifique.] [International Council of Scientific Unions. Scientific Committee on Antarctic Research. International Association of Scientific Hydrology. Commission of Snow and Ice.] International Symposium on Antarctic Glaciological Exploration (ISAGE), Hanover, New Hampshire, U.S.A., 3-7 September 1968, p. 97-1 15.

Thomas, R. H. I973[a]. The creep of ice shelves: theory. Journal of Glaciology, Vol. 12, No. 64, p. 45-53.

Thomas, R. H. 1973[b]. The creep of ice shelves: interpretation of observed behaviour. Fournal of Glaciology, Vol. 12, No. 64, p. 55-70.

Weertman, J. 1957. Deformation of floating ice shelves. Journal of Glaciology, Vol. 3, No. 21, p. $3^{8-42 .}$ 